\title{
Recent Progress on Carbonaceous Material Engineering for Electrochemical Hydrogen Peroxide Generation
}

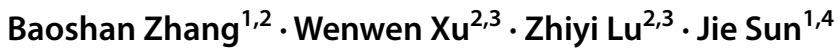

Received: 29 November 2019 / Revised: 20 January 2020 / Accepted: 12 February 2020 / Published online: 7 March 2020

(c) The Author(s) 2020

\begin{abstract}
Electrochemical synthesis of hydrogen peroxide $\left(\mathrm{H}_{2} \mathrm{O}_{2}\right)$ provides a clean and safe technology for large-scale $\mathrm{H}_{2} \mathrm{O}_{2}$ production. The core of this project is the development of highly active and highly selective catalysts. Recent studies demonstrate that carbonaceous materials are favorable catalysts because of their low-cost and tunable surface structures. This brief review first summarizes the strategies of carbonaceous material engineering for selective two-electron $\mathrm{O}_{2}$ reduction reaction and discusses potential mechanisms. In addition, several device designs using carbonaceous materials as catalysts for $\mathrm{H}_{2} \mathrm{O}_{2}$ production are introduced. Finally, research directions are proposed for practical application and performance improvement.
\end{abstract}

Keywords Hydrogen peroxide $\cdot$ Carbonaceous materials $\cdot$ Heteroatom doping $\cdot$ Device design

\section{Introduction}

Hydrogen peroxide $\left(\mathrm{H}_{2} \mathrm{O}_{2}\right)$ is a highly valuable chemical, among the 100 most important chemicals in the world [1]. As an environmentally friendly oxidant, $\mathrm{H}_{2} \mathrm{O}_{2}$ can be used not only in various chemical industries and environmental remediation [2] but also as a potential energy carrier for numerous energy conversion processes [3]. At present, the industrial production of $\mathrm{H}_{2} \mathrm{O}_{2}$ is an energy-intensive anthraquinone process that requires complex, large-scale installations and expensive catalysts [3]. Furthermore, a large amount of organic waste is produced in this process. More importantly, due to the instability of $\mathrm{H}_{2} \mathrm{O}_{2}$, additional security precautions should be taken in transportation and

\section{Zhiyi Lu}

luzhiyi@nimte.ac.cn

Jie Sun

jies@tju.edu.cn

1 School of Chemical Engineering and Technology, Tianjin University, Tianjin 300072, China

2 Ningbo Institute of Materials Technology and Engineering, Chinese Academy of Sciences, Ningbo 315201, China

3 University of Chinese Academy of Sciences, Beijing 100049, China

4 State Key Laboratory of Organic-Inorganic Composites, Beijing University of Chemical Technology, Beijing 100029, China storage [4]. Therefore, having a low-cost and decentralized preparation scheme is necessary to solve the aforementioned problems [5]. Direct synthesis of $\mathrm{H}_{2} \mathrm{O}_{2}$ from $\mathrm{H}_{2}$ and $\mathrm{O}_{2}$ indicates a new direction; however, the risk of explosion is prominent and needs to be eliminated [6-8]. The direct production of $\mathrm{H}_{2} \mathrm{O}_{2}$ by two-electron $\mathrm{O}_{2}$ reduction reaction (ORR), which offers a fast, clean, and safe $\mathrm{H}_{2} \mathrm{O}_{2}$ generation technology, has attracted much attention. The reaction process is expressed as follows:

$\mathrm{O}_{2}+2 \mathrm{H}_{2} \mathrm{O}+2 \mathrm{e}^{-} \rightarrow \mathrm{H}_{2} \mathrm{O}_{2}+2 \mathrm{OH}^{-} \mathrm{U}^{0}=0.68 \mathrm{Vvs} . \mathrm{RHE}$

The two-electron ORR process has been practically used since the 1990s, and the key lies on active and selective catalyst screening [9]. Various catalysts have also been employed in electrochemical synthesis of $\mathrm{H}_{2} \mathrm{O}_{2}$ from twoelectron ORR process, and noble metal-based catalysts show the best performance $[10,11]$. However, finite reserves and high costs of precious metals limit their large-scale applications [12]. Alternatively, carbonaceous materials have been identified as efficient catalysts because of their abundance, high stability in electrochemical reactions, and tunable surface and structural properties [12-14].

In early studies in this field, pristine carbon materials were investigated as catalysts for ORR to produce $\mathrm{H}_{2} \mathrm{O}_{2}$; the activity and selectivity of such materials were relatively low $[15,16]$. Unsatisfactory performance was mainly attributed to the unsuitable electronic structure that cannot offer 
an optimized adsorption/desorption energy to the reaction intermediate $(* \mathrm{OOH})$. Thus, numerous strategies, including defect design [13, 17] and heteroatom doping [12, 18-25], have been adopted to optimize the electronic structure to improve the activity and selectivity of carbon materials (Fig. 1). In this brief review, the performance of defects and heteroatom-doped carbonaceous materials are first introduced and their reaction mechanisms are also presented. Then, several devices using carbonaceous materials as

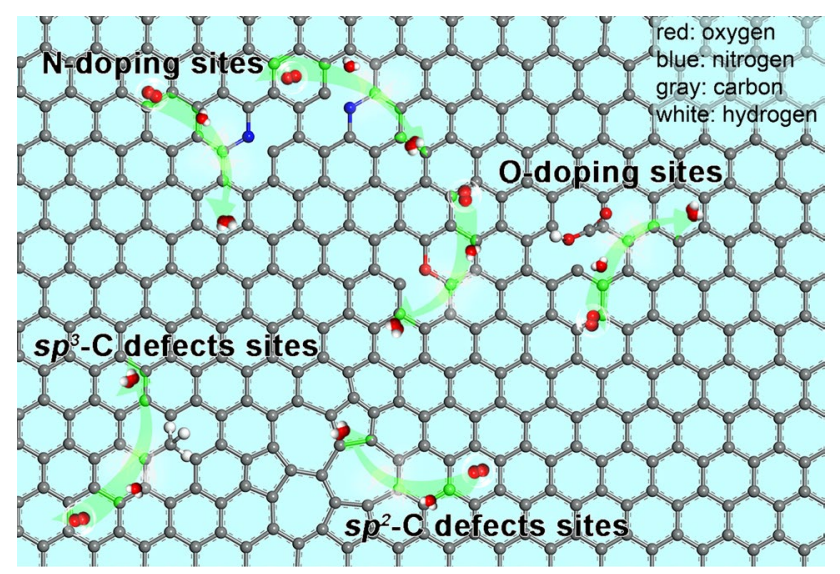

catalysts for $\mathrm{H}_{2} \mathrm{O}_{2}$ production are introduced. Finally, we propose that topological structure design for high-current density catalysts, long-term run, and other strategies for practical applications should be investigated in the future.

\section{Strategies in Carbonaceous Material Engineering}

\section{Defect Engineering in Carbonaceous Materials}

\section{$\mathrm{sp}^{3}-\mathrm{C}$ and Defects}

Liu et al. [17] proposed that defects and $\mathrm{sp}^{3}-\mathrm{C}$ in carbonaceous materials were the active sites for reactant adsorption or reactive sites in electrochemical processes, resulting in improvement of oxygen reduction kinetics. Thus, the researchers prepared hierarchically porous carbon (HPC, Fig. 2a) and revealed the positive effect of defects and $\mathrm{sp}^{3}-\mathrm{C}$ on $\mathrm{H}_{2} \mathrm{O}_{2}$ production. When the $I_{\mathrm{D}} / I_{\mathrm{G}}$ value of HPCs increased from 0.84 to 1.17 (Fig. 2b), the $\mathrm{H}_{2} \mathrm{O}_{2}$ production rate could be enhanced gradually, indicating a significant contribution of the $\mathrm{sp}^{3}-\mathrm{C}$ bonds and defects to enhance the electrocatalytic performance. Combined with high surface area and porosity, the material exhibited a high-current

Fig. 1 Two-electron ORR on carbonaceous materials

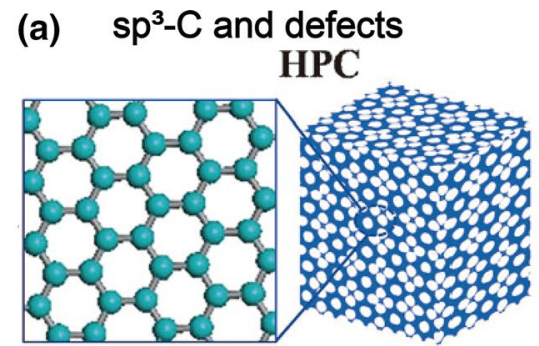

(d)

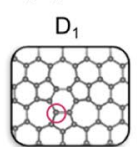

$s p^{2}-C$ defects
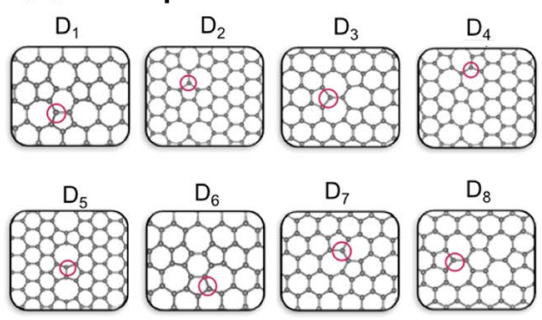

(b)

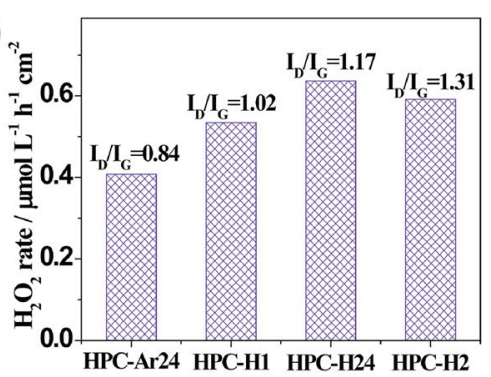

(e)

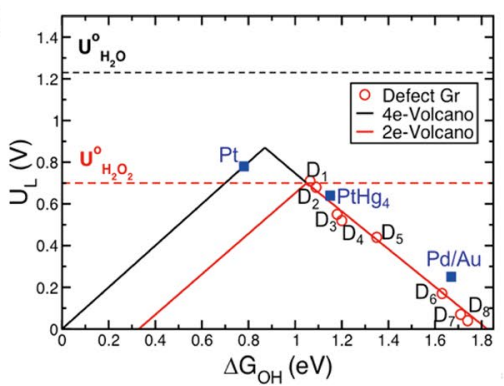

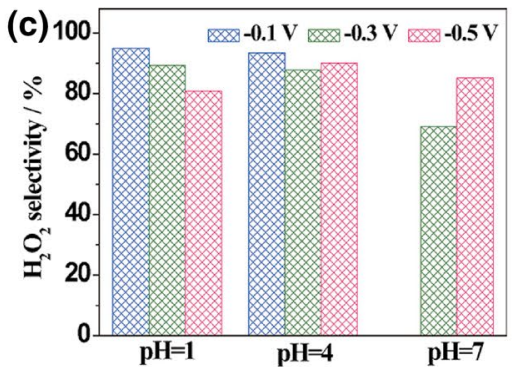

(f)

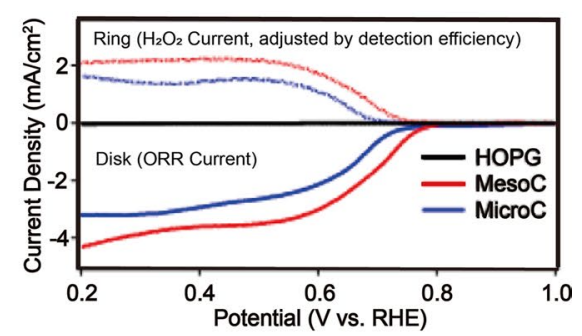

Fig. 2 Defects effect in carbon materials for two-electron ORR process. a Schematic illustration of HPC. b $\mathrm{H}_{2} \mathrm{O}_{2}$ production rate (normalized by BET surface area, $0.3 \mathrm{~V}, \mathrm{pH} 1$ ) of HPC-Ar24, HPC-H24, HPC-H1, and HPC-H2 with different contents of $\mathrm{sp}^{3}-\mathrm{C}$ and defects. (The number in HPC-Ar/HX $(X=24,1,2)$ indicates the carbonization time of MOF-5 precursor under $\mathrm{Ar} / \mathrm{H}_{2}$ atmosphere.) c $\mathrm{H}_{2} \mathrm{O}_{2}$ selectivity of HPC-H24 in acidic solution and neutral solution at different potentials. d $D_{1}-D_{8}$ are different defect-type configura- tions with nonhexagonal ring members. $\mathrm{D}_{1}$ and $\mathrm{D}_{6}$ display different active sites in 555-6-777 double vacancies. $\mathrm{D}_{2}$ and $\mathrm{D}_{4}$ are 555-777 line defects, and $\mathrm{D}_{2}$ indicates 55-8-55 line defects. $\mathrm{D}_{3}, \mathrm{D}_{7}$, and $\mathrm{D}_{8}$ are 555-777, 55-77, and 5555-6-7777 double vacancy defects, respectively. e Volcano plot of different $\mathrm{sp}^{2}-\mathrm{C}$ defects. $\mathbf{f}$ Disk current density and ring current density in $\mathrm{O}_{2}$-saturated $0.1 \mathrm{~mol} / \mathrm{L} \mathrm{KOH}$ at $1600 \mathrm{r} /$ min. Copyright 2017, American Chemical Society 
efficiency and high $\mathrm{H}_{2} \mathrm{O}_{2}$ production rate in both acidic and neutral solutions (Fig. 2c).

\section{$s p^{2}-C$ Defects}

Chen et al. [13] also investigated the effect of defects in porous carbon catalysts on ORR performance. The mesoporous carbon and microporous carbon prepared with a large number of $\mathrm{sp}^{2}$-C defects (Fig. 2d) exhibited high selectivity and activity for $\mathrm{H}_{2} \mathrm{O}_{2}$ production. To understand the role of defects in oxygen reduction, the researchers also investigated a wide variety of defect configurations (Fig. 2d) through theoretical calculations. As shown in Fig. 2e, all the defect configurations were located on the right side of the two-electron volcano, which preserved $\mathrm{O}-\mathrm{O}$ bonds due to weak binding with oxygenated species and contributed to the formation of $\mathrm{H}_{2} \mathrm{O}_{2}$. Some types of defects had favorable energies of oxygenated species, and their activity may be higher than that of $\mathrm{PtHg}_{4}$ [10]. This result was consistent with the experimental characterizations that a variety of $\mathrm{sp}^{2}-\mathrm{C}$ defects improved the performance of porous carbon (Fig. 2f). The important role of defects for two-electron ORR was also investigated and demonstrated in other carbon materials [26-29].

\section{Heteroatom Doping of Carbonaceous Materials}

\section{Oxygen-Doped Carbonaceous Materials}

In addition to considering the defects of $\mathrm{C}$ atomic arrangement, heteroatom doping is another effective strategy to tune the electronic structure of carbonaceous materials. Santos et al. [16] conducted a comparative study on Printex L6 and Vulcan XC-72 R carbon for electrogeneration of $\mathrm{H}_{2} \mathrm{O}_{2}$ by reducing dissolved oxygen in an alkaline solution. The results showed that the Printex L6 was more effective than Vulcan XC-72 $\mathrm{R}$ for $\mathrm{H}_{2} \mathrm{O}_{2}$ production. The researchers thought the most likely difference between two carbon materials is the presence of more oxygenated acid species in Printex L6, which could provide greater hydrophilicity, thereby increasing the activity for $\mathrm{H}_{2} \mathrm{O}_{2}$ production [16]. The researchers further studied the materials after pre-treatment with nitric acid or ammonia. The results showed that acid-treated Printex L6 was the most suitable material for the two-electron pathway of the ORR because it contained the largest concentration of oxygenated acid species, which increased the hydrophilic character of the carbon support [30].

To deeply investigate the specific roles of oxygen-containing functional groups in ORR performance improvement, Lu et al. [12] demonstrated a facile and general approach to catalyst development through the surface oxidation of abundant carbon materials (Fig. 3a) to significantly enhance the activity and selectivity (approximately 90\%) for $\mathrm{H}_{2} \mathrm{O}_{2}$ production (Fig. 3c). Combined with theoretical calculations, the results revealed that the carbon atoms adjacent to several oxygen functional groups $(-\mathrm{COOH}$ and $\mathrm{C}-\mathrm{O}-\mathrm{C}$, Fig. 3a, b) were the active sites for oxygen reduction reaction via two-electron pathway. The experimental observations and theoretical calculations provided new insights into catalyst development that may be relevant in the production of industrial chemicals by means of clean, renewable electrical energy [12]. Kim et al. [18] also developed an easily scalable mild thermal reduction in graphene oxide ( $\mathrm{mrGO}$, Fig. 3d) to form $\mathrm{H}_{2} \mathrm{O}_{2}$ from oxygen. Their prepared few-layered mrGO (F-mrGO) exhibited highly selective and stable peroxide formation activity at low overpotentials $(<10 \mathrm{mV})$ under basic conditions (Fig. 3f), thereby exceeding the performance of current state-of-the-art alkaline catalysts. The performance of $\mathrm{H}_{2} \mathrm{O}_{2}$ production could be further improved by annealing at $600{ }^{\circ} \mathrm{C}$, as the density of active functional groups increased (Fig. 3e). Their findings revealed that $\mathrm{sp}^{2}$-hybridized carbon near-ring ether defects along sheet edges were the most active sites for peroxide production, providing new insights into the electrocatalytic design of carbon-based materials for effective peroxide production [18].

Sa et al. [31] also reported high activity for $\mathrm{H}_{2} \mathrm{O}_{2}$ production on carbon nanomaterials with enriched oxygenated carbon edges. Zhou et al. [32] studied activated carbon (AC) and revealed that the oxygen-containing groups on the $\mathrm{AC}$ function as oxygen reduction reaction sites for $\mathrm{H}_{2} \mathrm{O}_{2}$ electrogeneration. Furthermore, the oxygen functional groups on carbon materials were increased by the treatments of acid, alkali, electrochemical oxidation, and glow discharge plasma. All of these materials showed excellent properties of two-electron ORR [33-38]. These reports have proven that oxygen functional groups on carbon materials are effective for selective $\mathrm{O}_{2}$ reduction to produce $\mathrm{H}_{2} \mathrm{O}_{2}$.

\section{Nitrogen-Doped Carbonaceous Materials}

Nitrogen doping in carbonaceous materials has been used in oxygen reduction reaction. The doped nitrogen species play a crucial role in reaction selectivity. Indeed, the nitrogen can be doped in the forms of pyridinic-N, pyrrolic-N, graphitic-N, quaternary- $\mathrm{N}$, and $\mathrm{N}$-oxide, as presented in Fig. 4a and characterized in Fig. 4b [21]. Lee et al. [39] found that $\mathrm{N}$-doped carbon exhibited high electrocatalytic activity toward the two-electron ORR. Therefore, they fabricated $\mathrm{N}$-doped porous carbon for electrocatalytic production of $\mathrm{H}_{2} \mathrm{O}_{2}$ and the selectivity reached as high as $93 \%$. Although several researchers have proposed that pyridinic, pyrrolic, and graphitic nitrogen in porous carbon might contribute to the two-electron ORR, the specific active sites in N-doped carbon have not been clearly revealed [40-43]. 
(a)

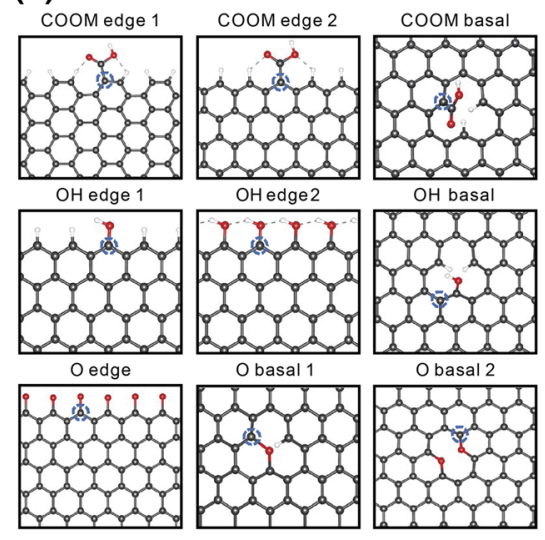

(d)

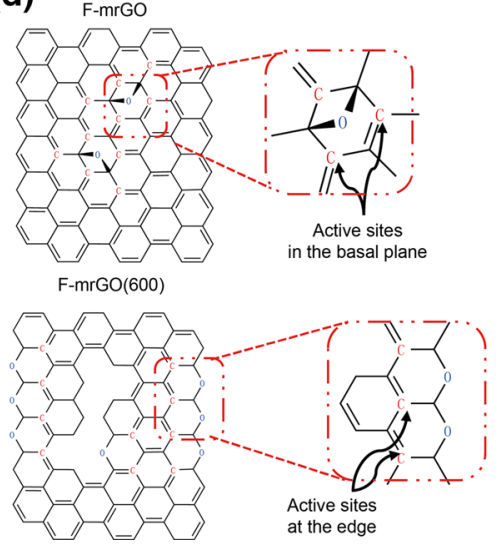

(b)

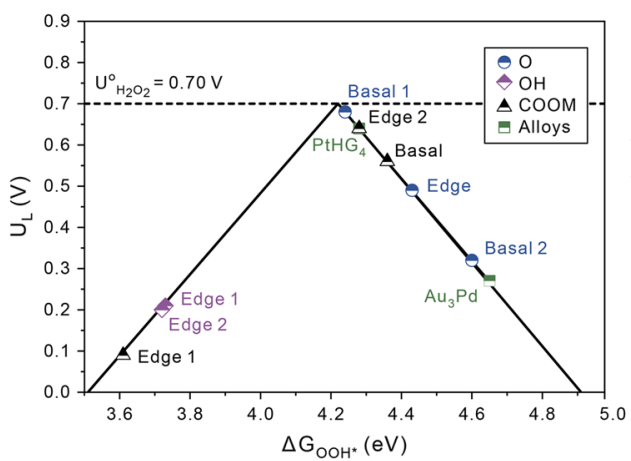

(e)

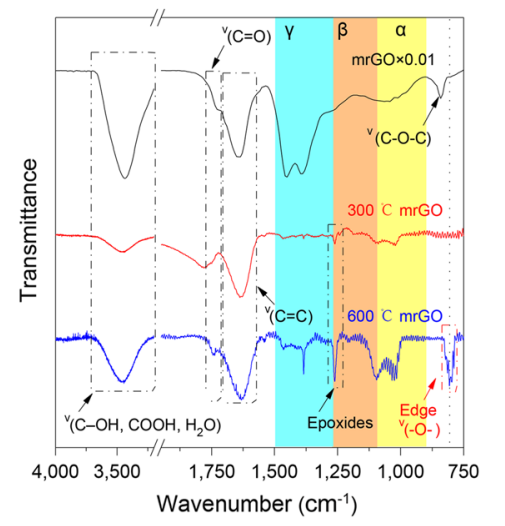

(c)

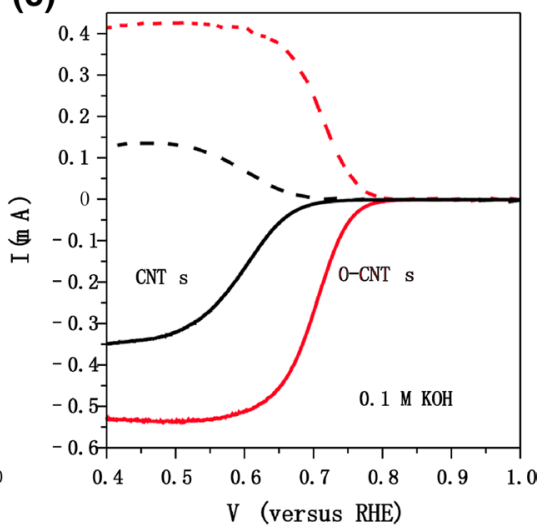

(f)

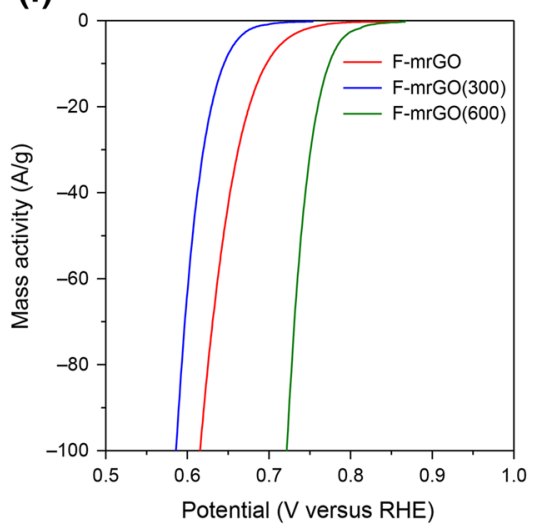

Fig. 3 a Different oxygen-doped type configurations (-COOM (M=H and $\mathrm{Na}$ ), $-\mathrm{OH}$, and $-\mathrm{C}-\mathrm{O}-\mathrm{C}$ ) on CNTs. b Volcano plot of different oxygen-doped type configurations for two-electron ORR displayed with limiting potential plotted as a function of adsorption energy of $\mathrm{OOH}^{*}$. c Disk and ring current for both catalysts in $0.1 \mathrm{~mol} / \mathrm{L} \mathrm{KOH}$

The specific action of nitrogen doping in carbon materials was demonstrated by subsequent reports. Perazzolo et al. [19] investigated nitrogen-doped mesoporous carbon as metal-free catalysts for $\mathrm{H}_{2} \mathrm{O}_{2}$ production, and a linear dependence of the nitrogen content on two-electron ORR performance was presented. They believe that the activity of nitrogen-doped carbon was related to the protonation/deprotonation of pyridinic-N, which led to increased activity at acid $\mathrm{pH}$ due to the protonation of nitrogen. Iglesias et al. also revealed that the pyridinic- $\mathrm{N}$ encounters difficulty in weakening the $\mathrm{O}-\mathrm{O}$ bond in acid solutions due to its protonation [44]; thus, it was more conducive to the generation of $\mathrm{H}_{2} \mathrm{O}_{2}$, which was consistent with previously reported results. By conducting comparison with other nitrogen-doped carbonaceous materials, the researchers also found that the high $\mathrm{N}_{\text {pyridinic }} / \mathrm{N}_{\text {pyrrole }}$ ratio in their catalysts would contribute to favorable selectivity [20].

Strasser et al. [21] deeply investigated the role of nitrogen-doped species in two-electron ORR based on porous at $1600 \mathrm{r} / \mathrm{min}$. d Illustration of active sites on F-mrGO and F-mrGO (600) at low overpotential. e FTIR spectra characterization of various mrGO powder samples. f Electrochemical measurement of F-mrGO with and without annealing for $\mathrm{O}_{2}$ reduction in $0.1 \mathrm{~mol} / \mathrm{L} \mathrm{KOH}$. Copyright 2018, Springer Nature

nitrogen-doped carbon materials. They found different activities and selectivity in various electrolytes (Fig. 4c). It was reported that the contents of pyridinic-N decreased in acid conditions and the graphitic- $\mathrm{N}$ decreased in neutral and alkaline conditions after electrochemical measurement. Meanwhile, the pyrrolic- $\mathrm{N}$ increased in all measurement environments. When $\mathrm{C}$ atoms neighboring pyridinic- $\mathrm{N}$ and graphitic-N are attached to the $\mathrm{OH}$ group, the N1s binding energy becomes extremely close to the pyrrolic-N, which is consistent with the content variety of nitrogen. Thus, the researchers believed that the pyridinic-N played a significant role in acid solutions, whereas the graphitic- $\mathrm{N}$ boosted the process of two-electron ORR in neutral and alkaline conditions, which is consistent with a subsequent report [45]. The $\mathrm{C}$ atoms neighboring $\mathrm{N}$-doped carbons were revealed as the active sites, and the role of pyridinic- $\mathrm{N}$ for two-electron ORR in acid conditions was affirmed again. As previously reported, pyridinic- $\mathrm{N}$ facilitates the charge transfer from the $\pi$ orbital to the antibonding orbital in $\mathrm{O}_{2}$ to weaken the $\mathrm{O}-\mathrm{O}$ 
Fig. 4 a Structure of different nitrogen-doped carbons. b Different N1s spectra of various $\mathrm{N}$-doped types in PEI50CMK3_800T (CMK-3 with $50 \mu \mathrm{L}$ polyethylenimine (PEI) aqueous solutions followed by annealing at $800^{\circ} \mathrm{C}$ ). c Electrochemical measurement of the optimized sample PEI50CMK3_800T in different pH. Copyright 2018, Wiley$\mathrm{VCH}$
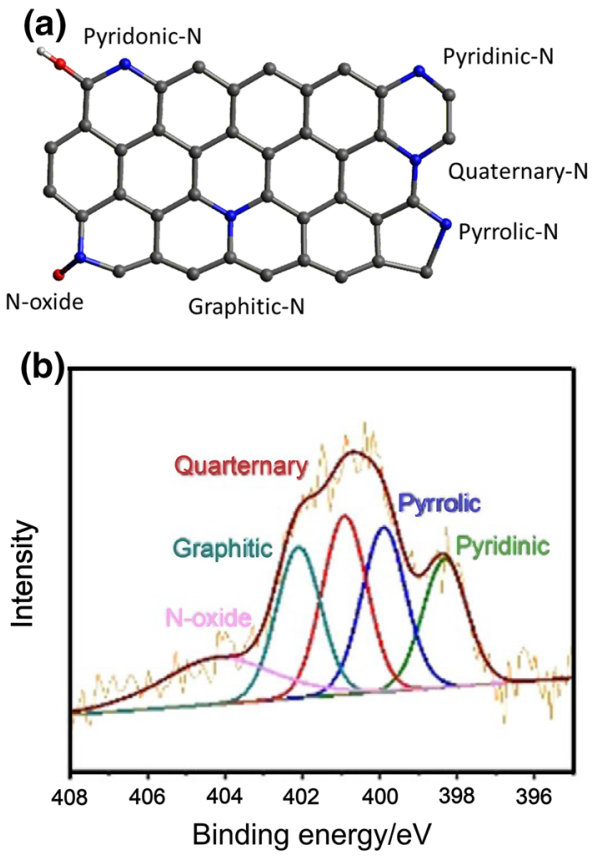

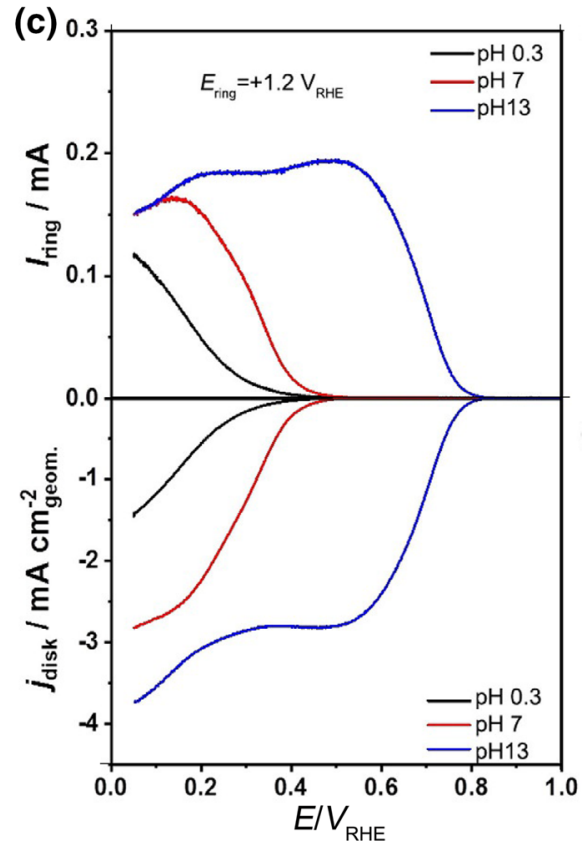

bond because of its delocalized lone pair electrons [46]. The pyridinic-N could prevent this effect by occupying the lone pair electrons to form an $\mathrm{N}-\mathrm{H}$ bond; thus, two-electron pathway occurred in acidic conditions, which was consistent with Refs.[19, 20, 47]. Although the pyridinic-N exhibited excellent selectivity for two-electron ORR, Strasser et al. [45] found that the selectivity would be decreased when the content of nitrogen-doped sites was extremely high. Therefore, having suitable nitrogen content was necessary for hydrogen peroxide production.

\section{Other Doped Carbonaceous Materials}

Similar to $\mathrm{N}$-doped carbon catalysts that activated $\pi$ electrons and induced charge redistribution, fluorine [22, 48], multiple elements [23, 25], doped carbon, and metal-nonmetal co-doped carbon [24, 49] also exhibited excellent performance for two-electron ORR. Zhao et al. [22] discussed fluorine-doped HPC for two-electron reduction. The experimental results and density functional theory (DFT) calculations revealed that incorporating $\mathrm{CF}_{2,3}$ into carbon plane promoted the activation of $\mathrm{O}_{2}$ and facilitated desorption of intermediate $\mathrm{OOH}$, which was crucial to $\mathrm{H}_{2} \mathrm{O}_{2}$ synthesis. The catalyst was also used in an electro-Fenton system, which could effectively remove single organic pollutants and even real refinery wastewater [48].

Two heteroatom co-doped carbonaceous materials have also been investigated for $\mathrm{H}_{2} \mathrm{O}_{2}$ production. For example, hexagonal boron nitride (h-BN) domains in boron-carbon-nitrogen materials showed better performance toward the two-electron ORR than the structures with single B or
$\mathrm{N}$ doping. As determined by DFT calculations, the interface between h-BN domains and graphene exhibited unique catalytic behavior that can preferentially drive the production of $\mathrm{H}_{2} \mathrm{O}_{2}$ [23]. Considering the promising activity and selectivity of oxygen functional groups and the nitrogen-doping modification in decreasing the overpotential, Zhao et al. [25] examined the synergistic effect of nitrogen dopants and $-\mathrm{COOH}$ groups on carbonaceous materials. Through theoretical calculations, the researchers found that the theoretical overpotential for two-electron ORR would be lower when the two groups combined in one carbon. To amplify the synergistic effect, they also designed metal-free carbon aerogel integrated with nitrogen dopants and surface $-\mathrm{COOH}$ groups for $\mathrm{H}_{2} \mathrm{O}_{2}$ production, which exhibited complete $100 \%$ selectivity to $\mathrm{H}_{2} \mathrm{O}_{2}$ with high yields and stability [25]. Furthermore, Cardoso et al. [50] discussed the performance varieties before and after electrochemically stabilized measurements on the $\mathrm{N}$ and $\mathrm{O}$ group-modified graphene and graphene oxide nanoribbons. The varieties of activity could be attributed to the changes of active functional groups in the process of long-term test. The results provided directions for the selection of stable catalysts in long-term preparation of $\mathrm{H}_{2} \mathrm{O}_{2}$.

Besides nonmetal modification, metal and nonmetal co-doped carbon materials are also favorable for oxygen reduction to $\mathrm{H}_{2} \mathrm{O}_{2}$ production. Oxygen could be effectively reduced on the $\mathrm{Co}-\mathrm{N}_{x}-\mathrm{C}$ site, but the main product is water, whereas the oxygen functional groups on carbon materials exhibited high selectivity for two-electron ORR with limited kinetics. Li et al. [49] prepared a $\mathrm{Co}-\mathrm{N}_{x}-\mathrm{C}$ site and oxygen functional group co-modified carbon catalyst combined 
with all advantages of aforementioned two materials, which improved activity and selectivity. Similarly, the transition metal single-atom coordination $\mathrm{Fe}-\mathrm{C}-\mathrm{O}$ as an efficient $\mathrm{H}_{2} \mathrm{O}_{2}$ catalyst exhibited excellent performance in alkaline and neutral $\mathrm{pH}$ [24]. Among four metal (Fe, $\mathrm{Pd}, \mathrm{Co}$, and $\mathrm{Mn}$ ) atom coordinations (see Fig. 5a), Fe coordination exhibited the best activity and selectivity, which was in agreement with their theoretical conclusions (Fig. 5b, c). This result provided many choices of coordination combinations for improving the performance of two-electron ORR. All of these materials present new strategies of catalyst design for oxygen reduction to $\mathrm{H}_{2} \mathrm{O}_{2}$.

\section{Device Development for $\mathrm{H}_{2} \mathrm{O}_{2}$ Production}

Device design is also a vital segment for the practical application of oxygen reduction to $\mathrm{H}_{2} \mathrm{O}_{2}$. Yamanaka et al. [15] used a previously reported solid polymer electrolyte (SPE) [51] to prepare $\mathrm{H}_{2} \mathrm{O}_{2}$ from $\mathrm{O}_{2}$ and water. Neutral $\mathrm{H}_{2} \mathrm{O}_{2}$ solutions could be continuously produced without any toxic byproducts through the method of complete exposure solid polymer electrolyte (Exp-SPE). As the electrosynthesis process should proceed at the three-phase boundary, the researchers improved the production rate by modifying the cathode with Nafion. The cathode side was coated with Nafion to maximize the active surface exposure, which resulted in significant enhancement of the electrocatalytic performance compared with the unmodified electrode [15]. Thereafter, the researchers designed a new apparatus by modifying the SPE and proposed an electrolysis method for direct production of neutral $\mathrm{H}_{2} \mathrm{O}_{2}$ solution from $\mathrm{O}_{2}$ and water. A detailed diagram of their installation is presented in Fig. 6a. The core components included cathode plate, Nafion-117 film, anode plate, and current collector, which are closely connected through flanges, bolts, nuts, and Teflon gaskets [52]. The apparatus provided a three-phase boundary for the electrosynthesis of $\mathrm{H}_{2} \mathrm{O}_{2}$, and the effect of boundary in the system was observed to have outstanding improvement performance through exposure cathode. Then, the researchers modified the cathode chamber with previous Nafion modification strategy [15]. Figure $6 \mathrm{~b}$ shows the effect of Nafion mass loading on the productivity of $\mathrm{H}_{2} \mathrm{O}_{2}$. The formation rate and concentration of $\mathrm{H}_{2} \mathrm{O}_{2}$ increased with the increase in Nafion mass loading and reached a plateau above $10 \mathrm{mg}$ loading.

Chen et al. [26] also designed a low-cost, membrane-free reactor for oxygen reduction to $\mathrm{H}_{2} \mathrm{O}_{2}$ production. Figure $6 \mathrm{c}$ shows the schematic of the reactor consisting of three core segments: working electrode in chamber 1 , production storage in chamber 2 , and chamber 3 for counterelectrode. The membrane-free system was achieved by the hydrophobic polymer-coated gas diffusion layer, which prevents water seepage but allows gas diffusion. The device could obtain $0.3 \mathrm{wt} \% \mathrm{H}_{2} \mathrm{O}_{2}$ through a two-hour operation without any chemical stabilizer additives. Moreover, a higher product concentration could also be achieved with a chemical stabilizer (Fig. 6d). The researchers also proposed four design criteria for $\mathrm{H}_{2} \mathrm{O}_{2}$ production through $\mathrm{O}_{2}$ reduction: (1) Decomposition of $\mathrm{H}_{2} \mathrm{O}_{2}$ should be minimized, (2) large production rate with high-current efficiency can be achieved at sufficiently high-current densities and low applied cell potentials, (3) product crossover should be prevented, and (4) the operation should be at ambient conditions [26]

\section{Outlook}

With their outstanding advantages in costs, reserves, stability, activity regulation, and selectivity for two-electron ORR, carbonaceous materials are high-potential catalysts (a)

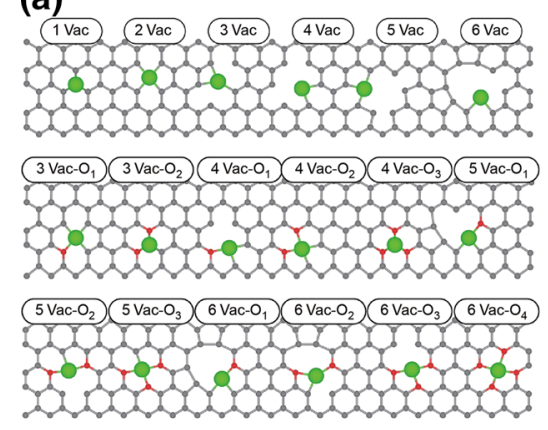

(b)

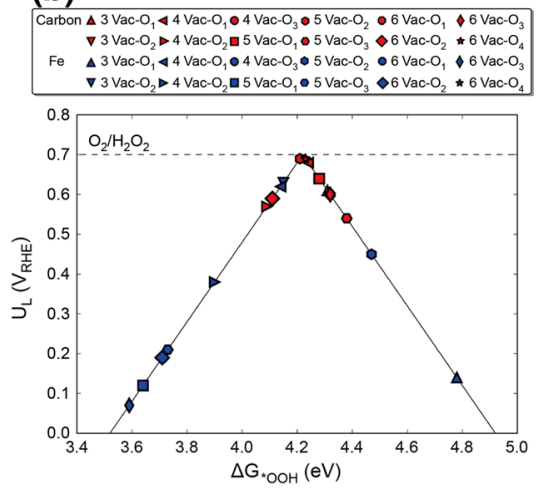

(c)

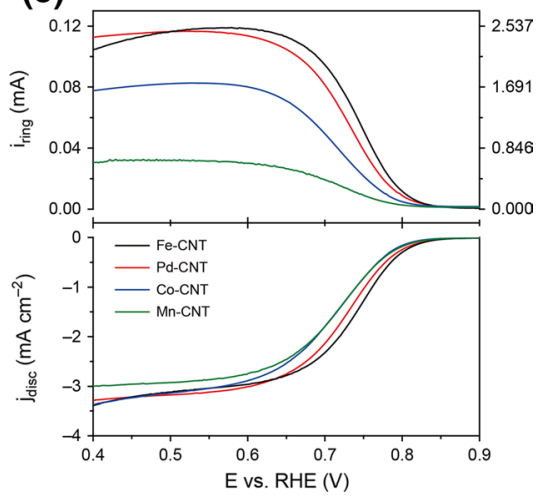

Fig. 5 a All types of Fe atoms coordinated in 2D carbon with and without $\mathrm{O}$ species ( $\mathrm{Fe}, \mathrm{O}$ or $\mathrm{N}$, and $\mathrm{C}$ atoms indicated by green, red, and gray markers). b Volcano plot for $2 \mathrm{e}^{-}$ORR process to $\mathrm{H}_{2} \mathrm{O}_{2}$ (* $\mathrm{OOH}$ adsorption at $\mathrm{C}$ and $\mathrm{Fe}$ indicated by red and blue markers, respectively). c Electrochemical measurement of CNT and Fe-, Pd-, Co-, and Mn-CNT catalysts in $0.1 \mathrm{~mol} / \mathrm{L} \mathrm{KOH}$ at $1600 \mathrm{r} / \mathrm{min}$. Copyright 2019, Springer Nature 


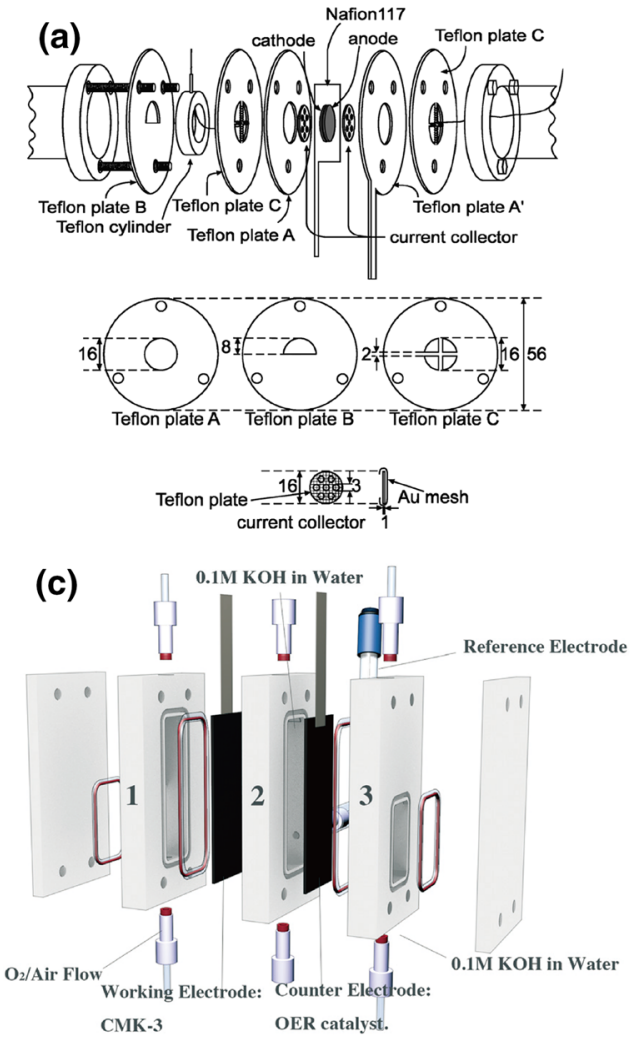

Fig. 6 a Cell structure illustration of Exp-SPE electrolysis (including cell assembly and details of Teflon plate and current). b The effect of Nafion mass loading at the modified AC + VGCF cathode on ExpSPE synthesis of $\mathrm{H}_{2} \mathrm{O}_{2}$. Copyright 2011, American Chemical Society.

for industrial electrochemical production of $\mathrm{H}_{2} \mathrm{O}_{2}$. However, the structure-activity relationship (especially the performance of single functional groups) remains unclear and needs to be further investigated by controllable experiments and precise DFT calculations. Other suitable catalysts can be found through DFT computations [53]. In addition, further attention should be given to topological structure design for active catalysts (actual determination of selectivity should be noted [54]) with high-current density, long-term run, and depressing the decomposition of $\mathrm{H}_{2} \mathrm{O}_{2}$ at high overpotentials. The catalysts may be low stability at high-current density, and reasonable experiments and characterization techniques should be applied to find the factors of material degradation [14] and provide targeted solutions. Combined with rational device design, the two-electron ORR process is expected to have other commercial applications in the future.

Acknowledgements This study was supported by Tianjin Science and Technology Project (No. 19YFSLQY00070), Foundation for State Key Laboratory of Organic-Inorganic Composites, Beijing University of Chemical Technology (No. oic-201901004), and Hundred Talent Program of the Chinese Academy of Sciences. (b)

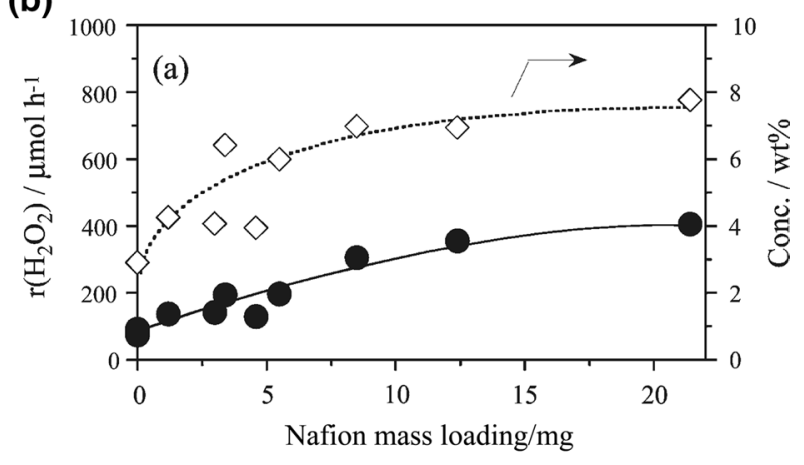

(d)

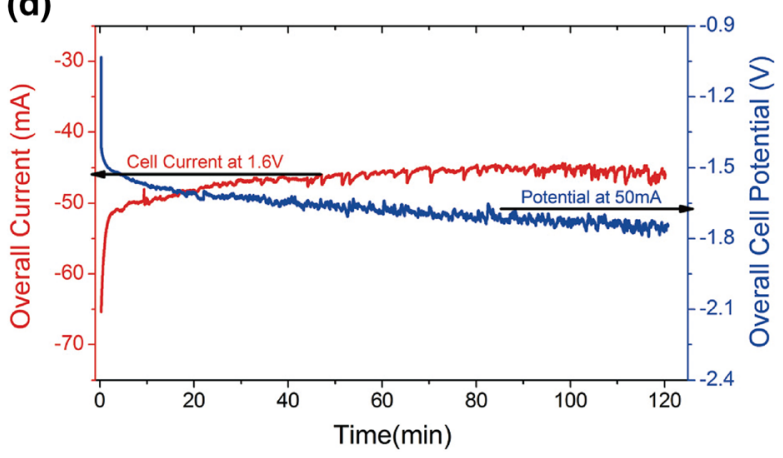

c Design diagram of membrane-free device. d Electrochemical measurement of membrane-free device. Copyright 2017, The Royal Society of Chemistry

Open Access This article is licensed under a Creative Commons Attribution 4.0 International License, which permits use, sharing, adaptation, distribution and reproduction in any medium or format, as long as you give appropriate credit to the original author(s) and the source, provide a link to the Creative Commons licence, and indicate if changes were made. The images or other third party material in this article are included in the article's Creative Commons licence, unless indicated otherwise in a credit line to the material. If material is not included in the article's Creative Commons licence and your intended use is not permitted by statutory regulation or exceeds the permitted use, you will need to obtain permission directly from the copyright holder. To view a copy of this licence, visit http://creativecommons.org/licenses/by/4.0/.

\section{References}

1. Myers RL (2007) The 100 most important chemical compounds: a reference guide. Greenwood Press, London, UK

2. Fukuzumi S, Yamada Y, Karlin KD (2012) Hydrogen peroxide as a sustainable energy carrier: electrocatalytic production of hydrogen peroxide and the fuel cell. Electrochimica Acta 82:493-511

3. Campos-Martin JM, Blanco-Brieva G, Fierro JLG (2006) Hydrogen peroxide synthesis: an outlook beyond the anthraquinone process. Angew Chem Int Ed 45(42):6962-6984 
4. Shi XJ, Siahrostami S, Li GL et al (2017) Understanding activity trends in electrochemical water oxidation to form hydrogen peroxide. Nat Commun 8(1):701

5. Jiang YY, Ni PJ, Chen CX et al (2018) Selective electrochemical $\mathrm{H}_{2} \mathrm{O}_{2}$ production through two-electron oxygen electrochemistry. Adv Energy Mater 8(31): 1801909

6. Edwards JK, Solsona B, Edwin NN et al (2009) Switching off hydrogen peroxide hydrogenation in the direct synthesis process. Science 323(5917):1037-1041

7. Samanta C (2008) Direct synthesis of hydrogen peroxide from hydrogen and oxygen: an overview of recent developments in the process. Appl Catal A: Gen 350(2):133-149

8. Edwards JK, Freakley SJ, Lewis RJ et al (2015) Advances in the direct synthesis of hydrogen peroxide from hydrogen and oxygen. Catal Today 248:3-9

9. Yang S, Verdaguer-Casadevall A, Arnarson L et al (2018) Toward the decentralized electrochemical production of $\mathrm{H}_{2} \mathrm{O}_{2}$ : a focus on the catalysis. ACS Catal 8(5):4064-4081

10. Siahrostami S, Verdaguer-Casadevall A, Karamad M et al (2013) Enabling direct $\mathrm{H}_{2} \mathrm{O}_{2}$ production through rational electrocatalyst design. Nature Mater 12(12):1137-1143

11. Verdaguer-Casadevall A, Deiana D, Karamad M et al (2014) Trends in the electrochemical synthesis of $\mathrm{H}_{2} \mathrm{O}_{2}$ : enhancing activity and selectivity by electrocatalytic site engineering. Nano Lett 14(3):1603-1608

12. Lu ZY, Chen GX, Siahrostami S et al (2018) High-efficiency oxygen reduction to hydrogen peroxide catalysed by oxidized carbon materials. Nat Catal 1(2):156-162

13. Chen SC, Chen ZH, Siahrostami S et al (2018) Defective carbonbased materials for the electrochemical synthesis of hydrogen peroxide. ACS Sustain Chem Eng 6(1):311-317

14. Perry SC, Pangotra D, Vieira L et al (2019) Electrochemical synthesis of hydrogen peroxide from water and oxygen. Nat Rev Chem 3(7):442-458

15. Yamanaka I, Murayama $\mathrm{T}$ (2008) Neutral $\mathrm{H}_{2} \mathrm{O}_{2}$ synthesis by electrolysis of water and $\mathrm{O}_{2}$. Angew Chem Int Ed 47(10):1900-1902

16. Assumpção MHMT, De Souza RFB, Rascio DC et al (2011) A comparative study of the electrogeneration of hydrogen peroxide using Vulcan and Printex carbon supports. Carbon 49(8):2842-2851

17. Liu YM, Quan X, Fan XF et al (2015) High-yield electrosynthesis of hydrogen peroxide from oxygen reduction by hierarchically porous carbon. Angew Chem Int Ed 54(23):6837-6841

18. Kim HW, Ross MB, Kornienko N et al (2018) Efficient hydrogen peroxide generation using reduced graphene oxide-based oxygen reduction electrocatalysts. Nat Catal 1(4):282-290

19. Perazzolo V, Durante C, Pilot R et al (2015) Nitrogen and sulfur doped mesoporous carbon as metal-free electrocatalysts for the in situ production of hydrogen peroxide. Carbon 95:949-963

20. Iglesias D, Giuliani A, Melchionna M et al (2018) N-doped graphitized carbon nanohorns as a forefront electrocatalyst in highly selective $\mathrm{O}_{2}$ reduction to $\mathrm{H}_{2} \mathrm{O}_{2}$. Chem 4(1):106-123

21. Sun YY, Li S, Jovanov ZP et al (2018) Structure, activity, and faradaic efficiency of nitrogen-doped porous carbon catalysts for direct electrochemical hydrogen peroxide production. ChemSusChem 11(19):3388-3395

22. Zhao K, Su Y, Quan X et al (2018) Enhanced $\mathrm{H}_{2} \mathrm{O}_{2}$ production by selective electrochemical reduction of $\mathrm{H}_{2} \mathrm{O}_{2}$ on fluorine-doped hierarchically porous carbon. J Catal 357:118-126

23. Chen SC, Chen ZH, Siahrostami S et al (2018) Designing boron nitride islands in carbon materials for efficient electrochemical synthesis of hydrogen peroxide. J Am Chem Soc 140(25):7851-7859

24. Jiang K, Back S, Akey AJ et al (2019) Highly selective oxygen reduction to hydrogen peroxide on transition metal single atom coordination. Nat Commun 10(1):3997
25. Zhao HY, Shen XQ, Chen Y et al (2019) A COOH-terminated nitrogen-doped carbon aerogel as a bulk electrode for completely selective two-electron oxygen reduction to $\mathrm{H}_{2} \mathrm{O}_{2}$. Chem Commun 55(44):6173-6176

26. Chen ZH, Chen SC, Siahrostami S et al (2017) Development of a reactor with carbon catalysts for modular-scale, low-cost electrochemical generation of $\mathrm{H}_{2} \mathrm{O}_{2}$. React Chem Eng 2(2):239-245

27. Yang YR, He F, Shen YF et al (2017) A biomass derived N/Ccatalyst for the electrochemical production of hydrogen peroxide. Chem Commun 53(72):9994-9997

28. Colić V, Yang S, Révay Z et al (2018) Carbon catalysts for electrochemical hydrogen peroxide production in acidic media. Electrochimica Acta 272:192-202

29. Han L, Sun YY, Li S et al (2019) In-plane carbon lattice-defect regulating electrochemical oxygen reduction to hydrogen peroxide production over nitrogen-doped graphene. ACS Catal 9(2): 1283-1288

30. Moraes A, Assumpção MHMT, Simões FC et al (2016) Surface and catalytical effects on treated carbon materials for hydrogen peroxide electrogeneration. Electrocatalysis 7(1):60-69

31. Sa YJ, Kim JH, Joo SH (2019) Active edge-site-rich carbon nanocatalysts with enhanced electron transfer for efficient electrochemical hydrogen peroxide production. Angew Chem Int Ed 58(4):1100-1105

32. Zhou W, Rajic L, Chen L et al (2019) Activated carbon as effective cathode material in iron-free Electro-Fenton process: integrated $\mathrm{H}_{2} \mathrm{O}_{2}$ electrogeneration, activation, and pollutants adsorption. Electrochimica Acta 296:317-326

33. Pan Z, Wang K, Wang Y et al (2018) In-situ electrosynthesis of hydrogen peroxide and wastewater treatment application: a novel strategy for graphite felt activation. Appl Catal B: Environ 237:392-400

34. Wang Y, Yi M, Wang K et al (2019) Enhanced electrocatalytic activity for $\mathrm{H}_{2} \mathrm{O}_{2}$ production by the oxygen reduction reaction: rational control of the structure and composition of multi-walled carbon nanotubes. Chin J Catal 40(4):523-533

35. Zhou L, Zhou MH, Zhang C et al (2013) Electro-Fenton degradation of p-nitrophenol using the anodized graphite felts. Chem Eng J 233:185-192

36. Miao J, Zhu H, Tang Y et al (2014) Graphite felt electrochemically modified in $\mathrm{H}_{2} \mathrm{SO}_{4}$ solution used as a cathode to produce $\mathrm{H}_{2} \mathrm{O}_{2}$ for pre-oxidation of drinking water. Chem Eng $\mathbf{J}$ 250:312-318

37. Zhou W, Rajic L, Meng XX et al (2019) Efficient $\mathrm{H}_{2} \mathrm{O}_{2}$ electrogeneration at graphite felt modified via electrode polarity reversal: utilization for organic pollutants degradation. Chem Eng J 364:428-439

38. Khataee A, Sajjadi S, Pouran SR et al (2017) A comparative study on electrogeneration of hydrogen peroxide through oxygen reduction over various plasma-treated graphite electrodes. Electrochimica Acta 244:38-46

39. Lee Y-H, Li F, Chang K-H et al (2012) Novel synthesis of $\mathrm{N}$-doped porous carbons from collagen for electrocatalytic production of $\mathrm{H}_{2} \mathrm{O}_{2}$. Appl Catal B: Environ 126:208-214

40. Fellinger TP, HaschéF SP et al (2012) Mesoporous nitrogen-doped carbon for the electrocatalytic synthesis of hydrogen peroxide. $\mathrm{J}$ Am Chem Soc 134(9):4072-4075

41. Park J, Nabae Y, Hayakawa T et al (2014) Highly selective twoelectron oxygen reduction catalyzed by mesoporous nitrogendoped carbon. ACS Catal 4(10):3749-3754

42. Sheng X, Daems N, Geboes B et al (2015) N-doped ordered mesoporous carbons prepared by a two-step nanocasting strategy as highly active and selective electrocatalysts for the reduction of $\mathrm{O}_{2}$ to $\mathrm{H}_{2} \mathrm{O}_{2}$. Appl Catal B: Environ 176-177:212-224 
43. Perazzolo V, Durante C, Gennaro A (2016) Nitrogen and sulfur doped mesoporous carbon cathodes for water treatment. J Electroanal Chem 782:264-269

44. Wan K, Yu ZP, Li XH et al (2015) pH effect on electrochemistry of nitrogen-doped carbon catalyst for oxygen reduction reaction. ACS Catal 5(7):4325-4332

45. Sun YY, Sinev I, Ju W et al (2018) Efficient electrochemical hydrogen peroxide production from molecular oxygen on nitrogen-doped mesoporous carbon catalysts. ACS Catal 8(4):2844-2856

46. Yamazaki SI, Yamada Y, Ioroi T et al (2005) Estimation of specific interaction between several Co porphyrins and carbon black: Its influence on the electrocatalytic $\mathrm{O}_{2}$ reduction by the porphyrins. J Electroanal Chem 576(2):253-259

47. Zhang JY, Zhang HC, Cheng MJ et al (2019) Tailoring the electrochemical production of $\mathrm{H}_{2} \mathrm{O}_{2}$ : strategies for the rational design of high-performance electrocatalysts. Small. https://doi.org/10.1002/ smll.201902845

48. Zhao K, Quan X, Chen S et al (2018) Enhanced electro-Fenton performance by fluorine-doped porous carbon for removal of organic pollutants in wastewater. Chem Eng J 354:606-615

49. Li BQ, Zhao CX, Liu JN et al (2019) Electrosynthesis of hydrogen peroxide synergistically catalyzed by atomic $\mathrm{Co}-\mathrm{N}_{x}-\mathrm{C}$ sites and oxygen functional groups in noble-metal-free electrocatalysts. Adv Mater 31(35):1904044

50. Cardoso ESF, Fortunato GV, Maia G (2019) Modification of C, $\mathrm{O}$, and $\mathrm{N}$ groups for oxygen reduction reaction on an electrochemically stabilized graphene nanoribbon surface. J Phys Chem C 123(26):16308-16316

51. Ogumi Z, Nishio K, Yoshizawa S (1981) Application of the SPE method to organic electrochemistry-II. Electrochemical hydrogenation of olefinic double bonds. Electrochim Acta 26(12):1779-1782

52. Murayama T, Yamanaka I (2011) Electrosynthesis of neutral $\mathrm{H}_{2} \mathrm{O}_{2}$ solution from $\mathrm{O}_{2}$ and water at a mixed carbon cathode using an exposed solid-polymer-electrolyte electrolysis cell. J Phys Chem C 115(13):5792-5799

53. Guo XY, Lin SR, Gu JX et al (2019) Simultaneously achieving high activity and selectivity toward two-electron $\mathrm{O}_{2}$ electroreduction: the power of single-atom catalysts. ACS Catal 9(12):11042-11054

54. Cardoso ESF, Fortunato GV, Maia G (2018) Use of rotating ringdisk electrodes to investigate graphene nanoribbon loadings for the oxygen reduction reaction in alkaline medium. ChemElectroChem 5(13):1691-1701

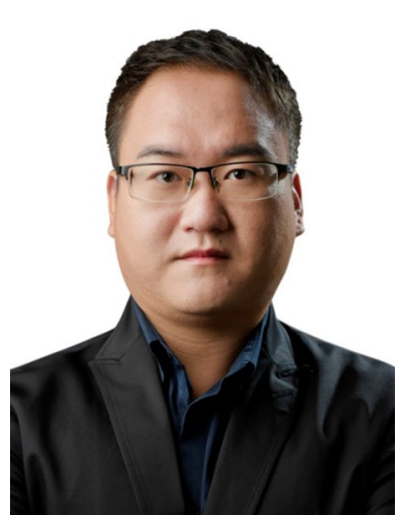

Zhiyi Lu is currently a Professor in Ningbo Institute of Materials Engineering and Technology, Chinese Academy of Sciences. $\mathrm{He}$ obtained his $\mathrm{PhD}$ degree in Chemical Engineering from Beijing University of Chemical Technology in 2015. His research group has been focused on developing next-generation nanomaterials for energy and environmental applications including chemical/fuel generation and water treatment.

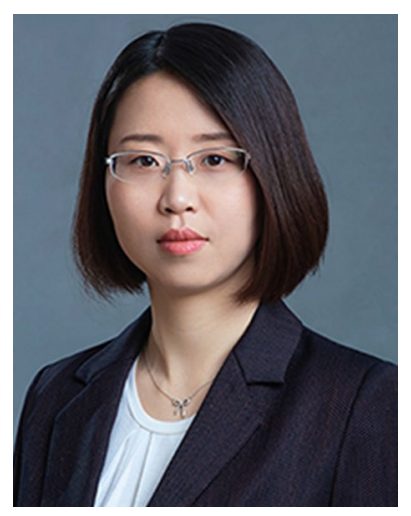

Jie Sun is a professor at the Tianjin University, China. She earned her PhD from the Beijing University of Chemical Technology and then worked as a postdoctoral at the Stanford University. Her current research interests focus on the development of multifunctional nanomaterials for energy conversion and storage, including Li-ion, Na-ion, $\mathrm{K}$-ion, and $\mathrm{Mg}$-ion batteries, lithium-sulfur batteries, as well as electrocatalysis. 